\title{
Pengaruh Permainan Kecil Berdasarkan Tingkat Motor Educability Terhadap Motivasi Dan Keterampilan Passing Permainan Futsal
}

\author{
Deny Syahrial $^{1}$, Andun Sudijandoko ${ }^{2}$, Anung Priambodo ${ }^{3}$ \\ Program Studi Pendidikan Olahraga. Pascasarjana Universitas Negeri Surabaya \\ Coresponding author: deny.17070805037@mhs.unesa.ac.id
}

\begin{abstract}
Abstrak. Penelitian ini bertujuan mengkaji pengaruh permainan kecil berdasarkan tingkat motor educability terhadap motivasi dan keterampilan passing permainan futsal. Subjek penelitian adalah ekstrakurikuler SDIT Ghilmani Surabaya sebanyak 64 siswa yang dibagi menjadi 4 kelompok. Kelompok eksperimen berdasarkan tingkat motor educability tinggi dan rendah diberikan latihan permainan kecil attack 1-2-1 dan menjala ikan, kelompok kontrol berdasarkan tingkat motor educability tinggi dan rendah tidak diberikan latihan permainan kecil attack 1-2-1 dan menjala ikan. Jenis penelitian ini menggunakan penelitian kuantitatif dengan metode quasi experiment. Rancangan penelitian menggunakan factorial design, serta analisis data menggunakan uji-t dan anova two way. Proses pengambilan data dilakukan dengan skala Likert untuk motivasi belajar dan ketrampilan passing untuk mendapat data pada saat pretest dan posttest. Hasil penelitian menunjukkan bahwa data pretest dan posttest dari analisis menggunakan SPSS, masing-masing kelompok yaitu (a) kelompok perlakuan menggunakan permainan kecil berdasarkan motor educability tinggi dan rendah terhadap motivasi belajar diperoleh rerata $06,31 \%$ dan untuk passing futsal diperoleh rerata $06,90 \%$ dengan sig $<0,05$. (b) kelompok kontrol tidak menggunakan permainan kecil berdasarkan motor educability tinggi dan rendah terhadap motivasi belajar diperoleh rerata $01,37 \%$ dan untuk passing futsal diperoleh rerata $01,40 \%$ dengan sig $>0,05$. Berdasarkan hasil penelitian dapat disimpulkan bahwa terdapat peningkatan motivasi belajar dan keterampilan passing futsal untuk kelompok eksperimen setelah diberi perlakuan permainan kecil dilihat dari hasil uji-t, serta pengaruhnya yang signifikan ditunjukan melalui uji anova. Generalisai hasil penelitian dapat disimpulkan bahwa permainan kecil efektif pada kelompok eksperimen terhadap motivasi belajar dan passing futsal.
\end{abstract}

Kata kunci: Permainan Kecil, Motor Educability, Motivasi, Keterampilan Passing.

\section{PENDAHULUAN}

Proses pendidikan dalam sekolah tentunya tidak lepas dari beberapa mata pelajaran yang ada dalamnya, salah satunya yaitu mata pelajaran pendidikan jasmani olahraga dan kesehatan (PJOK). Tujuan mata pelajaran PJOK menuntut siswa untuk memiliki kebugaran yang bagus melalui beberapa tugas gerak dari yang ringan sampai yang kompleks. Pengembangan potensi peserta didik sebagaimana dimaksud dalam tujuan pendidikan nasional dapat diwujudkan melalui kegiatan intrakurikuler, kokurikuler, dan ekstrakurikuler. Pendidikan jasmani adalah bagian dari pendidikan keseluruhan yang mengutamakan aktivitas jasmani dan pembinaan hidup sehat untuk pertumbuhan dan perkembangan jasmani, mental, sosial dan emosional yang serasi, selaras dan seimbang (Kristiyandaru, 2010). Menurut Marantika (2012) kegiatan ekstrakurikuler dilakukan untuk mengembangkan para siswa dengan kebutuhan, potensi, bakat, dan minat mereka. Melalui ekstrakurikuler, maka peserta didik secara sadar melakukan aktivitas fisik sekaligus memperoleh pendidikan sehingga peserta didik dapat mengembangkan potensi fisik, mengoptimalkan gerak dasar dan juga menemukan karakternya sendiri. Selain itu, motivasi siswa dalam mengikuti ekstrakurikuler penting untuk diperhatikan.

Memperhatikan motivasi siswa merupakan salah satu syarat penting untuk mengajak siswa agar memperhatikan apa yang diinstruksikan, karena apabila siswa mempunyai motivasi yang bagus terhadap suatu materi maka akan memperlancar atau memberikan proses belajar mengajar yang interaktif tanpa ada paksaan untuk melakukan suatu tugas. Menurut Hamalik (2009) selain guru ada salah satu yang mempengaruhi hasil belajar mengajar yaitu motivasi. Motivasi adalah suatu proses untuk menggiatkan motif atau motif-motif menjadi tindakan atau perilaku untuk memenuhi kebutuhan dalam mencapai tujuan (Nursalim, 2007). Proses ekstrakurikuler tentunya seringkali memberikan tugas langsung praktek saat di lapangan. Hal tersebut tentunya membutuhkan minat yang bagus dari siswa untuk mengikuti proses ekstrakurikuler. Menumbuhkan motivasi siswa tentunya tidaklah mudah, banyak cara untuk mewujudkannya diantaranya melalui metode 
belajar yang digunakan, pembawaan seorang guru, dan media yang digunakan. Selain motivasi, keterampilan passing dalam permainan futsal yang mungkin dapat meningkatkan kemampuan motorik siswa.

Dalam permainan futsal terdapat beberapa keterampilan yang harus dicapai siswa. Salah satu keterampilan dasar yang harus dimiliki seorang siswa adalah keterampilan passing. Passing merupakan teknik dasar yang paling sering digunakan dalam permaian futsal dan memiliki kesulitan tersendiri bagi siswa, karena siswa dengan latar belakang yang berbeda-beda tentunya memiliki penguasaan motorik yang berbedabeda juga, oleh karena itu diharapkan dalam penyampaian materi, seorang guru harus kreatif agar siswa tidak bosan dan tertarik untuk mencoba dan melakukan passing. Selain keterampilan passing permainan passing ada hal yang harus diperhatikan oleh guru dan pelatih yaitu metode belajar yang digunakan. Metode belajar yang digunakan oleh seorang guru, sangat berpengaruh besar terhadap minat siswa dalam mengikuti proses ekstrakurikuler. Untuk mendukung metode belajar yang baik tentunya membutuhkan media-media pendukung. Dalam permainan futsal media-media pendukung bisa berupa sarana prasarana. Namun seringkali dalam suatu sekolah sarana prasarana olahraga seringkali kurang memadai hal tersebut mengakibatkan seorang guru kebingungan untuk memberikan materi. Selain itu pada kemajuan teknologi dan gadget pada jaman sekarang sangat pesat dan merambah kepada para siswa. Hal tersebut berdampak pada siswa yang kecanduan gadget sehingga siswa malas untuk melakukan aktivitas fisik. Untuk itu diperlukan suatu metode yang sesuai agar siswa tertarik dan antusias dalam mengikuti ekstrakurikuler salah satunya yaitu melalui metode bermain.

Mengingat tujuan PJOK adalah memperkaya gerak siswa, maka dirasa tepat pada masa sekolah merupakan masa dimana para siswa senang bermain, tidak hanya anak usia dini saja bahkan remaja maupun dewasa juga membutuhkan bermain untuk mencukupi kebutuhan gerak yang kompleks sekaligus bersifat rekreasi (Hartati dkk., 2012). Selain itu Hartati dkk. (2012) juga mengatakan bahwa bermain dan permainan adalah suatu kegiatan yang sangat dibutuhkan dalam kehidupan manusia. Setiap insan manusia pada dasarnya membutuhkan aktivitas bermain tidak hanya untuk meningkatkan perkembangan fisik, tetapi juga sosial, intelektual, dan emosional seseorang. Melihat kegunaan atau manfaat bermain bagi seseorang, maka bisa dikatakan metode ini bisa digunakan guru dalam proses pembelajaran.

Masa remaja merupakan masa tahap pengembangan kemampuan gerak dasar lokomotor, non-lokomotor dan manipulatif. Ketika memasuki masa Sekolah Dasar (SD) dapat dikatakan dengan rentang usia 10-15 tahun (Caskey, 2014). Tentunya penguasaan motoriknya bermacam-macam dari penguasaan motorik yang tinggi dan penguasaan motorik yang rendah. Hal tersebut dapat berpengaruh terhadap keterampilan geraknya. Seperti yang dikatakan oleh Mesnan (2015) interpretasi untuk motor educability menunjukan bagaimana seseorang merasa senang atau mudah dalam belajar keterampilan olahraga. Kemampuan motor educability setiap siswa berbeda-beda. Kemampuan motor educability ini dapat dibedakan menjadi dua kategori yaitu tingkat motor educability tinggi dan tingkat motor educability rendah. Untuk menarik minat siswa terhadap ekstrakurikuler tentunya seorang guru harus inovatif. Metode belajar dengan menggunakan permainan kecil tentu diharapkan dapat menarik minat siswa agar lebih antusias dalam mengikuti proses belajar mengajar ekstrakurikuler, karena dalam sebuah permainan mengandung beberapa manfaat seperti yang dikatakan Hartati dkk., (2012) menyebutkan bahwa manfaat permainan yang didapat yaitu keceriaan, keterampilan baru dalam motorik halus dan kasar, sosialisasi, mengenal aturan, percaya diri, membantu perkembangan berpikir, dan perkembangan emosional yang baik.

Dari hasil pengamatan di lapangan peneliti melihat dan berdiskusi dengan pelatih ekstrakurikuler futsal di SDIT Ghilmani Surabaya, menurutnya motivasi siswa untuk 
berlatih teknik dasar futsal kurang baik dibandingkan keinginan siswa yang ingin langsung bermain futsal. Oleh sebab itu kemampuan passing yang dimiliki siswa kurang baik, ditunjukan pada saat siswa bermain futsal disisa waktu ekstrakurikuler. Peneliti melihat dan mengamati teknik passing siswa tidak akurat, sering sekali terjadi salah passing pada tim sendiri dan penguasaan permainan kurang baik. Kesalahan passing dalam permainan futsal dapat berakibat fatal, tidak jarang dalam permainan futsal counter attack tim lawan datang dari kesalahan passing dan kemampuan passing yang kurang baik.

Hasil studi terdahulu menunjukkan bahwa permainan, motor educability tinggi, dan motivasi dapat meningkatkan kemampuan motor skill, motivasi belajar, dan kemampuan siswa dalam mempelajari teknik baru. Adapun perbedaan penelitian terdahulu dengan kajian dalam penelitian ini antara lain variabel yang dipengaruhi, dan cabang olahraganya, kemudian keunggulan penelitian ini dibandingkan penelitian sebelumnya adalah peneliti menganalisis variabel yang mempengaruhi meningkatnya motor skill bahwa siswa dengan motor educability yang bagus lebih baik dari siswa lainnya. Permainan juga dapat meningkatkan keterampilan motorik dan motivasi belajar siswa. Oleh karena itu, studi ini bermaksud mengeksplorasi pengaruh permainan kecil berdasarkan tingkat motor educability terhadap motivasi dan keterampilan passing permainan futsal pada siswa ekstrakurikuler futsal SDIT Ghilmani Surabaya.

\section{METODE PENELITIAN}

Studi ini merupakan penelitian kuantitatif dengan metode quasi experimen. Rancangan penelitian menggunakan factorial design 2x2. Faktor pemilahnya adalah variabel moderator motor educability siswa. Pemilahan dibagi berdasarkan tingkat motor educability tinggi dan rendah. Penentuan motor educability dilakukan dengan cara mengambil skor median dari seluruh nilai yang telah diperoleh siswa. Apabila seorang siswa memiliki tingkat motor educability lebih tinggi dari median, maka siswa itu masuk ke dalam kelompok dengan tingkat motor educability tinggi. Sedangkan apabila siswa memiliki skor tingkat motor educability yang lebih rendah dari pada nilai median, maka siswa tersebut masuk ke dalam kelompok dengan tingkat motor educability rendah. Pemisahan kelompok berdasarkan tingkat motor educability ini bersifat semu. Artinya, dalam penelitian para siswa tidak dipisah secara nyata antara siswa yang memiliki tingkat motor educability tinggi dengan siswa yang memiliki tingkat motor educability rendah. Motor educability bertujuan untuk mengukur sejauh mana seseorang dapat mempelajari sesuatu kesanggupan motorik untuk melakukan gerakan atau teknik baru (New Motor Skill). Tidak semua orang memiliki tingkat motor educability yang sama, rendahnya motor educability juga dapat mempengaruhi seseorang dalam mempelajari atau melakukan gerakan baru (New Motor Skill). Untuk mengukur motor educability peneliti menggunakan IOWA Brace Test yang terdiri dari 21 jenis tes diantaranya 10 jenis tes yang diambil dari Brace Test yang memenuhi kriteria menurut Julianti dan Alawiyah (2016).

Subjek penelitian adalah ekstrakurikuler SDIT Ghilmani Surabaya sebanyak 64 siswa yang dibagi menjadi 4 kelompok. Kelompok eksperimen berdasarkan tingkat motor educability tinggi dan rendah diberikan latihan permainan kecil attack 1-2-1 dan menjala ikan, kelompok kontrol berdasarkan tingkat motor educability tinggi dan rendah tidak diberikan latihan permainan kecil attack 1-2-1 dan menjala ikan. Proses pengambilan data dilakukan dengan skala Likert untuk motivasi belajar dan keterampilan passing untuk mendapat data pada saat pretest dan posttest. Tes yang disusun untuk mengukur keterampilan teknik dasar bermain futsal meliputi: passing, controlling, dribbling dan shooting. Analisis data pretest dan posttest dianalisis menggunakan uji-t dan anova dengan uji normalitass dan homogenitas sebagai uji prasyarat. 


\section{HASIL DAN PEMBAHASAN}

Deskripsi data hasil pretest dan posttest tiap kelas untuk motivasi dan keterampilan passing ditunjukkan pada Tabel 1 .

Tabel 1. Deskripsi data hasil pretest dan posttest

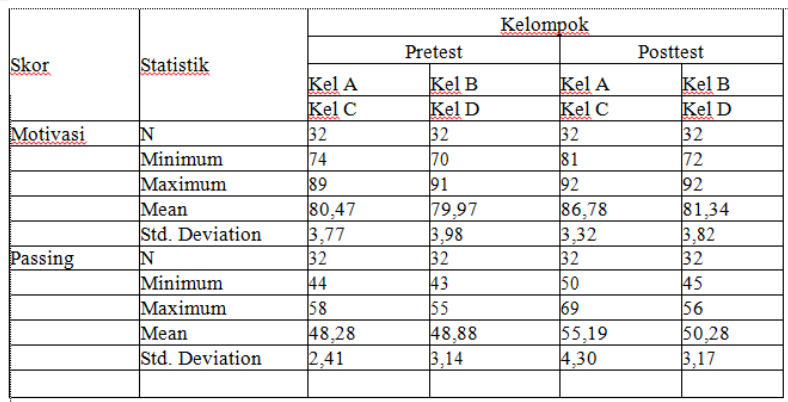

Dari hasil tes motivasi dan passing futsal, pada pretest kelompok perlakuan dengan permainan kecil berdasarkan tingkat motor educability tinggi dan rendah diperoleh rerata $80,47 \%$ dan 48,28\%, sedangkan kelompok kontrol tanpa diberikan latihan diperoleh rerata $79,97 \%$ dan $48,88 \%$. Setelah diberikan latihan pada kelompok perlakuan, hasil posttest motivasi dan passing futsal diperoleh rerata $85,78 \%$ dan 55,19\%, sedangkan kelompok kontrol, hasil posttest motivasi dan passing futsal diperoleh rerata $81,34 \%$ dan $50,28 \%$. Selanjutnya, hasil uji normalitas dan homogenitas disajikan pada Tabel 2 dan Tabel 3.

Tabel 2. Hasil uji normalitas

\begin{tabular}{|c|c|c|c|c|c|c|c|c|c|}
\hline \multirow{3}{*}{ Skor } & \multirow{3}{*}{ Statistik } & \multicolumn{8}{|c|}{ Kelompok } \\
\hline & & \multicolumn{4}{|c|}{ Pretes } & \multicolumn{4}{|c|}{ Postes } \\
\hline & & Kel A & Kel C & Kel B & Kel D & Kel A & Kel C & Kel B & Kel D \\
\hline \multirow[t]{3}{*}{ Motivasi } & Statistic & 0,98 & 0,90 & 0,98 & 0,91 & 0,96 & 0,89 & 0,98 & 0,87 \\
\hline & df & 16,00 & 16,00 & 16,00 & 16,00 & 16,00 & 16,00 & 16,00 & 16,00 \\
\hline & Sig. & 0,93 & 0,08 & 0,94 & 0,12 & 0,67 & 0,05 & 0,86 & 0,08 \\
\hline \multirow[t]{3}{*}{ Passing } & Statistic & 0,94 & 0,87 & 0,89 & 0,95 & 0,92 & 0,83 & 0,95 & 0,96 \\
\hline & $\mathrm{df}$ & 16,00 & 16,00 & 16,00 & 16,00 & 16,00 & 16,00 & 16,00 & 16,00 \\
\hline & Sig. & 0,40 & 0,07 & 0,07 & 0,57 & 0,19 & 0,08 & 0,12 & 0,59 \\
\hline
\end{tabular}

Tabel 3. Hasil uji homogenitas

Tabel 3. Hasil uji homogenitas

\begin{tabular}{|l|c|c|c|c|}
\hline \multirow{2}{*}{ Kelompok } & \multicolumn{4}{|c|}{ Levene } \\
\cline { 2 - 5 } & Statistic & df1 & df2 & Sig. \\
\hline Tingkat Motor Educability dan Motivasi & 1,28 & 3,00 & 60,00 & 0,28 \\
\hline Tingkat Motor Educability dan Passing & 1,67 & 3,00 & 60,00 & 0,18 \\
\hline
\end{tabular}

Hasil uji normalitas menggunakan uji shapiro wilk dan uji homogenitas menggunakan levene's test pada taraf signifikansi $5 \%$ menunjukkan data tersistribusi normal dan homogen.
Selanjutnya dilakukan uji hipotesis, pengujian hipotesis yang pertama memiliki tujuan untuk mengetahui apakah terdapat pengaruh dari perlakuan yang digunakan dalam penelitian. Penelitian ini menggunakan dua jenis perlakuan untuk mengukur dua variabel yang berbeda. Perlakuan pertama adalah permainan kecil degan pola attack 1-2-1, dan perlakuan kedua adalah permainan kecil menjala ikan. Variabel yang diukur adalah motivasi dan passing futsal. Terdapat variabel moderator yaitu tingkat motor educability. Hasil uji $\mathrm{t}$ disajikan pada Tabel 4.

Tabel 4. Hasil uji $\mathrm{t}$

\begin{tabular}{|l|l|c|c|c|c|c|}
\hline Tabel 4. Hasil uji t \\
\hline \multirow{2}{*}{ Variabel } & $\begin{array}{l}\text { Tingkat ME dengan } \\
\text { Kelompok }\end{array}$ & Mean & Std. Dev. & t & df & $\begin{array}{c}\text { Sig. (2- } \\
\text { tailed) }\end{array}$ \\
\hline \multirow{2}{*}{ Motivasi } & Perlakuan & $-6,31$ & 1,97 & $-18,08$ & 31,00 & 0,00 \\
\cline { 2 - 8 } & Kontrol & $-1,37$ & 0,60 & $-01,16$ & 31,00 & 0,25 \\
\hline \multirow{2}{*}{ Passing } & Perlakuan & $-6,90$ & 3,49 & $-11,20$ & 31,00 & 0,00 \\
\cline { 2 - 8 } & Kontrol & $-1,40$ & 0,91 & $-0,78$ & 31,00 & 0,44 \\
\hline
\end{tabular}

Berdasarkan Tabel 4 diketahui bahwa nilai Sig pada kelompok perlakuan $<0,05$. Hasil ini jatuh pada daerah kritik untuk menolak Ho dan menerima Hi. Sebaliknya nilai Sig pada kelompok kontrol > 0,05. Hasil ini jatuh pada daerah penerimanaan Ho dan penolakan Hi. Maka dapat disimpulkan bahwa terdapat pengaruh yang diberikan oleh kelompok perlakuan baik pada variabel motivasi maupun passing futsal dan sebaliknya pada kelompok kontrol tidak terdapat pengaruh pada variabel motivasi dan passing futsal.

Pengujian selanjutnya digunakan untuk mengetahui apakah terdapat interaksi antara tingkat motor educability terhadap jenis permainan pada variabel keterampilan passing futsal dan motivasi siswa. Pengujian ini merupakan kelanjutan dari hasil analisis anova two way. Interaksi dari dua variabel ini ditunjukkan pada grafik pada Gambar 1 dan Gambar 2.

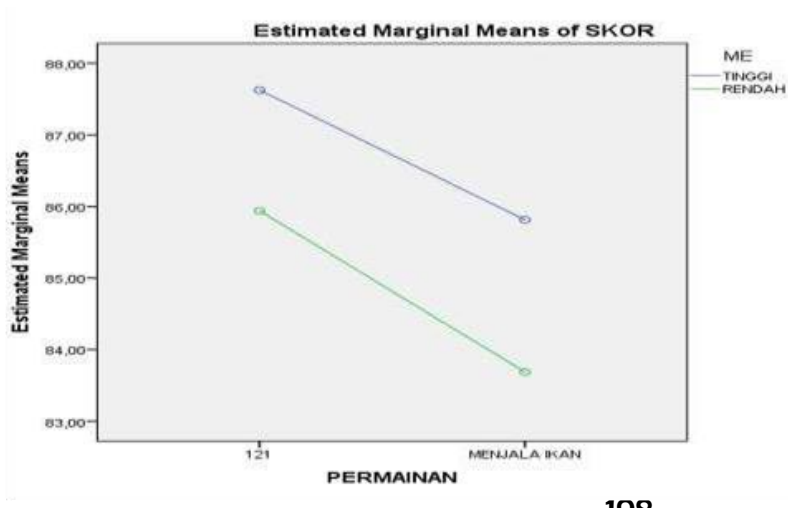


Gambar 1. Interaksi antara jenis permainan dan tingkat motor educability pada skor motivasi

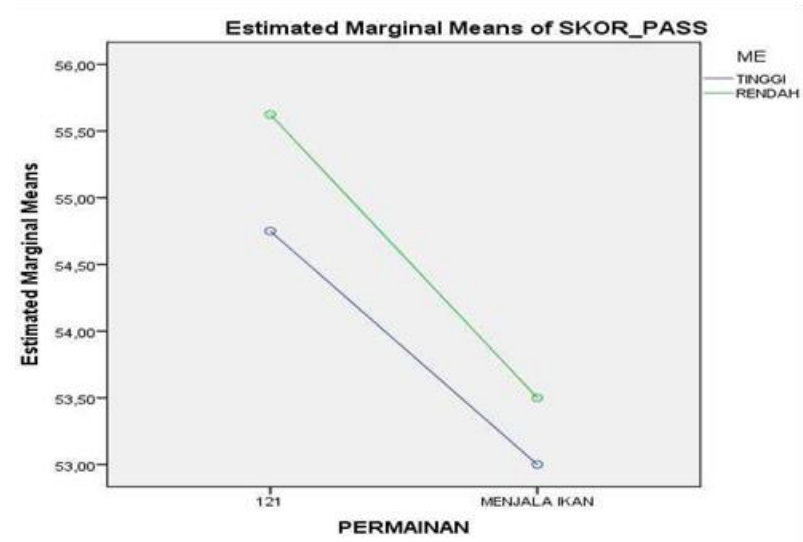

Gambar 2. Interaksi antara jenis permainan berdasarkan tingkat motor educability pada skor passing futsal

Berdasarkan Gambar 1 dan Gambar 2 diketahui bahwa tidak terdapat perpotongan garis antara hubungan ME tinggi dan ME rendah pada jenis permainan. Maka disimpulkan bahwa tidak terdapat interaksi antara tingkat ME dan jenis permainan pada variabel passing dan motivasi siswa.

Berdasarkan hasil analisa data yang dilakukan terdapat pengaruh permainan kecil berdasarkan tingkat motor educability tinggi dan rendah, hal tersebut dapat dilihat dari nilai signifikan dari variabel motivasi $<0,05$. Hal yang sama dikemukakan oleh Julianti \& Tuti (2016) Setelah peserta ekstrakulikuler mendapat perlakuan dengan menggunakan permainan kecil, dilakukan post test untuk membuktikan perubahan dari perlakuan yang diberikan. Dengan demikian ada pengaruh positif dari permainan kecil terhadap motor educability peserta ekstrakulikuler. Hal serupa yang diungkapkan oleh Pahliwandari (2014) terdapat hubungan yang positif antara motor educability, kebugaran jasmani dan motivasi belajar secara bersama-sama dengan hasil belajar pendidikan jasmani. Dalam studi ini pemberian permainan kecil dengan tingkat motor educability yang berbeda-beda dapat berpengaruh terhadap motivasi belajar siswa.

Hasil studi ini juga menunjukkan bahwa bahwa terdapat pengaruh yang signifikan antara variabel yang diteliti, demikian pula yang diungkapkan oleh
Sarmento (2016) analisis permainan futsal semestinya tidak hanya mencakup aksi permainan di lapangan saja, namum sebaiknya pemain futsal yang dapat dihasilkan dari lapangan khususnya pola atau strategi untuk menciptakan gol. Demikian juga Lukmanto (2016) untuk menjadi pemain futsal yang baik, setidaknya pemain harus menguasai keterampilan atau teknik dasar futsal, diantaranya meliputi: mengumpan bola (passing), mengumpan lambung (chipping), menguasai bola (controlling), menggiring bola (dribbling), menyundul bola (heading) dan menembak bola (shooting). Selanjutnya teknik keterampilan futsal hampir sama dengan sepak bola, hanya perbedaan yang paling mendasar dalam futsal banyak mengontrol atau menahan bola dengan menggunakan telapak kaki (sole), karena permukaan lapangan yang keras para pemain harus menahan bola tidak boleh jauh dari kaki, karena apabila jauh dari kaki dengan ukuran lapangan yang kecil pemain lawan akan mudah merebut bola. Selain itu, pergerakan pemain yang terus menerus juga menyebabkan pemain harus terus melakukan operan (passing). Tak heran bila 90\% permainan futsal diisi oleh passing (Murhananto, 2006).

Berdasarkan hasil uji hipotesis, untuk mengetahui pengaruh motivasi dan keterampilan passing permainan futsal siswa yang menggunakan latihan permainan kecil, dapat dilihat dari hasil uji Anova (Analysis Of Variance) two way. Pada hasil terdapat pengaruh motivasi dan keterampilan passing permainan futsal siswa yang menggunakan latihan permainan kecil, ditunjukan pada hasil uji pengaruh sig $<0,05 \%$. Ada beberapa hal yang perlu diperhatikan dalam bermain futsal seperti yang diungkapkan oleh Ridlo (2016) Kemampuan motorik merupakan hasil gerak individu dalam melakukan gerak, baik gerak yang bukan gerak olahraga maupun gerak dalam olahraga atau kematangan penampilan keterampilan motorik. Selanjutnya Nurhasan (2007) kemampuan motorik berasal dari bahasa Inggris yaitu motorabilty. Gerak (motorik) merupakan suatu aktivitas yang sangat penting bagi manusia, karena dengan 
gerak (motor) manusia dapat meraih sesuatu yang menjadi harapannya.

Berdasarkan uji hipotesis, untuk mengetahui terdapat interaksi antara permainan kecil berdasarkan tingkat motor educability tinggi dan rendah terhadap motivasi dan keterampilan passing permainan futsal siswa, dapat dilihat dari hasil uji Anova (Analysis Of Variance) two way. Ditunjukan dengan grafik bahwa tidak terdapat hubungan berdasarkan tingkat motor educability tinggi dan rendah pada permainan kecil dan hal yang serupa terjadi pada motivasi dan keterampilan passing futsal siswa. Dapat ditarik kesimpulan bahwa Ho diterima, ditunjukan dengan hasil analisis jatuh pada daerah kritik penolakan $\mathrm{Hi}$, bahwa tidak ada interaksi antara permainan kecil berdasarkan tingkat motor educability terhadap motivasi belajar dan keterampilan passing futsal siswa. Dari hasil anilisis dapat dipengaruhi beberapa faktor seperti yang diungkapkan oleh Noviada, dkk (2014) Hal ini disebabkan karena intensitas latihan yang sangat minim, fasilitas yang kurang memadai, metode latihan atau metode pengajaran yang kurang efektif karena kurangnya kombinasi antara proses latihan dengan bermain, model pelatihan yang diajarkan atau dilatihkan tidak menekankan pada teknik dasar, kurangnya kemampuan beradaptasi terhadap penguasaan keterampilan atau kemampuan gerak (motor ability) yang rendah, serta faktor lingkungan berlatih yang kurang mendukung. Peneliti menyadari bahwa siswa memiliki kemampuan gerak (motor) yang berbeda-beda tingkatannya, sehingga dapat mempengaruhi siswa untuk dapat mempelajari gerakan baru (new motor skill).

\section{KESIMPULAN}

Kesimpulan dalam penelitian ini, yaitu a) terdapat pengaruh secara signifikan permainan kecil berdasarkan tingkat motor educability tinggi dan rendah terhadap motivasi permainan futsal siswa, b) terdapat pengaruh secara signifikan permainan kecil berdasarkan tingkat motor educability tinggi dan rendah terhadap keterampilan passing permainan futsal siswa, c) terdapat pengaruh secara signifikan antara motivasi dan keterampilan passing permainan futsal siswa yang menggunakan latihan permainan kecil berdasarkan tingkat motor educability, dan d) tidak terdapat pengaruh yang berarti antara permainan kecil berdasarkan tingkat motor educability tinggi dan rendah terhadap motivasi dan keterampilan passing permainan futsal siswa.

\section{SARAN}

Untuk meningkatkan motivasi belajar dan keterampilan passing permainan futsal tidak hanya dilakukan dengan latihan yang monoton dan membosankan, dengan menggunakan latihan permainan kecil siswa dapat merasa senang dan gembira mengikuti kegiatan ekstrakurikuler selanjutnya, latihan menggunakan permainan kecil yang sesuai dengan tujuan secara tidak langsung akan memberikan pengaruh terhadap motivasi belajar dan keterampilan passing futsal, peneliti tidak menampik bahwa perlu proses untuk mendapatkan hasil yang optimal dari sebuah latihan menggunakan permainan kecil.

\section{DAFTAR PUSTAKA}

Arias, J. L., Argundo, F. M., \& Alonso, J. I. (2011). Review of Rule Modification in Sport. Journal of Sports Science and Mediciene, 10(1), 1-8.

Bahagia, Y., \& Suherman, A. (2000). Prinsipprinsip Pengembangan dan Modifikasi Cabang Olahraga. Departemen Pendidikan Nasional.

Blegur, J., \& Rambu, M. P. W. (2018) Permainan Kecil: Teori dan Aplikasi. Kupang: Jusuf Aryani Learning.

Caskey, M. M., Anfara, V. A., \& Jr. (2007). Research summary: Young adolescents' developmental characteristics. authorized administrator of PDXScholar. Retrieved 6/14/ 2013, from http://www.nmsa.org/Research/Resear chSummaries/DevelopmentalCharacte ristics/tabid/1414/Default.aspx.

Das, J. (2014). A Study On Physical Fitness and Motor Educability Of Different Age Group . International Research Journal of Commerce Arts and Science, 5(10), 11-15. 
Dehkordi, M. R. (2017). The Educational Impact of Traditional Games: the Role of Zurkhaneh Sport in Educating Children. International Journal of Science Culture and Sport, 5(3), 134139.

Demir, K. (2011). Teachers Intrinsic and Extrinsic Motivation as Predictors of Student Engagement. New World Science Academy, 6(2), 1397-1409.

Fajriyanto, A. (2018). Pengaruh Gaya Mengajar dan Motor Educability terhadap Hasil Belajar Passing Atas Permainan Bolavoli, Jurnal Pendidikan Jasmani Kesehatan dan Rekreasi Edisi 1 Tahun 2018, http://journal.student.uny.ac.id/ojs/ojs/ index.php/pjkr/article/viewFile/10634/ 10174 [9-1-2020]

Ghosh, S., Heifetz, A., \& Verbrugge, R. (2015). Do Players Reason by Forward Induction in Dynamic Perfect Information Games? In: Ramanujam, $R$. (ed.) Proceedings of the 15th Conference on Theoretical Aspects of Rationality and Knowledge 2015, EPTCS 215, 2016, 159-175.

Hamalik, O. (2010). Psikologi Belajar \& Mengajar. Bandung. Sinar Baru Algesindo.

Hartati, S. C. Y., Priambodo, A., \& Kristiyandaru, A. (2013). Permainan Kecil (Cara Efektif Mengembangkan Fisik, Motorik, Keterampilan Sosial, dan Emosional). Malang: Wineka Media.

Irawan, A. (2009). Teknik Dasar Modern Futsal. Jakarta: Pena Pundi Aksara.

Julianti, R. R., \& Tuti, A. (2016). Pengaruh Permainan Kecil Terhadap Motor Educability. Jurnal Ilmiah PENJAS, 2(2), 77-87.

Lhaksana, J. (2012). Taktik \& Strategi Futsal Modern. Jakarta: Be Champion.

Komarudin. (2015). An Analytical Study of the Stunt Type Test as a Measure of Motor Educability. Research Quarterly. American Physical Education Association, 8(3), 46-55.
Kristiyandaru, A. (2010). Manajemen Pendidikan Jasmani dan Olahraga. Surabaya: Unesa University Press.

Mahardika, I. S. (2017). Evaluasi Pengajaran. Surabaya: Unesa University Press.

Mahmud. (2011). Metode Penelitian Pendidikan. Bandung: Pustaka Setia.

Maksum, A. (2011). Membangun Mental Prestatif: Tugas Utama Pendidikan ke Depan. In Sirikit Syah \& Martadi (Eds.), "Rekontruksi Pendidikan". Surabaya: Unesa University Press.

Maksum, A. (2012). Metodologi Penelitian dalam Olahraga. Surabaya: Unesa University Press.

Marantika. (2012). Kegiatan Ekstrakurikuler. diakses dari (http://man6jkt.sch.id/new/?page-id35), tanggal 28 mei 2019.

Marhendro A. S. D., \& Saryono. (2012). Tes Keterampilan Dasar Bermain Futsal. Yogyakarta: FIK-UNY.

Marhaendro, A. S. D. (2014). Validity and Reability of Futsal Skill Test. International Seminar of Sport Culture and Achievement. ISSCA2014 Proceedings:157-164. Diperoleh dari https://www.researchgate.net/profile/N adia_Narruti2/publication/305500105 Relationship_Between_Percentage_of Body_Fat_and_Somatotype_Athletes _of_PencakSilat_Combative_Class_R egional_Training_PELATDA_Daerah Istimewa_Yogyakarta/links/57a401b d08aefe6167aa32cc/RelationshipBetween-Percentage-of-Body-Fat-andSomatotype-Athletes-of-PencakSilatCombative-Class-Regional-TrainingPELATDA-Daerah-IstimewaYogyakarta.pdf\#page $=292$

Mc. Cloy., C. H., \& Young, N. D. (1984). Test and Measurement in Health and Physical Education. New York: Appleton Century Crofts Inc.

Mesnan. (2015). The Effect of Teaching Method and The Motor Educability Towards Learning Result Skills to Play Basket Ball. Faculty of Sport Science, Medan State University: 
International Journal of Science and

Research (IJSR)., 6(4), 30-32.

Montolulu, B. E. F. (2009). Bermain dan

Permainan Anak. Jakarta: Universitas

Terbuka.

Mursalin. (2011, Febuari 11). Tahap Bermain Pada Anak. [Pesan web log]. Diperoleh dari http://mursalinnersboyz.blogspot.com/2011/02/tahap -perkembangan-bermain-padaanak.html.

Mutiah, D. (2010). Psikologi Bermain Anak Usia Dini. Jakarta: Kencana Prenada Media Group.

Nursalim, M. (2007). Psikologi Pendidikan. Surabaya: Unesa University Press.

Peraturan Menteri Pendidikan dan Kebudayaan Nomor 62 Tahun 2014 tentang Kegiatan Ekstrakurikuler pada Pendidikan Dasar dan Pendidikan Menengah. p. Pasal 3 Ayat 1.

Pradana, VO, \& Noval, A. (2018). Hubungan Motor Educability dan Percaya Diri Dengan Hasil Belajar Renang Gaya Bebas Pada Siswa Putra Kelas X SMA Budi Mulia Jakarta. Area Olahraga Jurnal, 3 (1), 79-86.

Quinn, T., \& Eckerson, T. (2010). Motivating Students to Read with Collaborative Reading Quizzer. National Council of Teachers of English, 100(1), 88-91. https://www.jstor.org/stable/20787699

Santrock, J. W. (2009). Perkembangan Anak. Jakarta: Erlangga.

Simanjuntak, V. (2018). Learning Result of Mawashi Geri Karate. Physical Education Study Program, Department of Sports Science. Universitas Tanjungpura, Pontianak: 2nd International Conference on Sports Sciences and Health 2018 (ICSSH 2018), 7, 191-195.

Soemitro. (1992). Permainan Kecil. Jakarta: Depdiknas.

Sudijandoko, A. (2010). Pembelajaran Pendidikan Jasmani yang Efektif dan Berkualitas. Jurnal pendidikan jasmani Indonesia, 7(1), 1-6.

Sugiyono. (2011). Metode Penelitian Kombinasi. Bandung: Alfabeta.
Sugiyono. (2013). Metode Penelitian Pendidikan (Pendekatan Kuantitatif, Kualitatif, dan R\&D). Bandung: Alfabeta.

Sukintaka. (1992). Modul Teori Bermain untuk D2 PGSD. Jakarta: DEPDIKBUD DIRJEN DIKTI Proyek Pembinaan Tenaga Kependidikan.

Sunarno, A. (1991). Huhungan Antara Motor Educability dengan Hasil Passing Bawah Dalam Olahraga Voli. Medan: FPOK-IKIP.

Supendi, P., \& Nurhidayat. (2016). 50 Permainan Indor dan Outdoor Mengasikkan. Jakarta: Penebar Swadaya Group.

Syamsuddin. (2014). Influences of Teaching Styles and Motor Educability on Learning Outcomes of Volleyball. Canadian Center of Science and Education, 10(5), 109-113

Ullah, M. I., Sagheer, A., Sattar, T., \& Khan, S. (2013). Factors Influencing Students Motivation to Learn in Bahauddin Zakariya University. Multan (Pakistan). International Journal of Human Resource Studies: 3(2). 90-108.

Uno, H. B. (2013). Teori Motivasi dan Pengukurannya: Analisis di Bidang Pendidikan. Jakarta: Bumi Aksara.

Usman, M. U., \& Setiawati, L. (1993). Upaya Optimalisasi Kegiatan Belajar Mengajar. Bandung: Remaja Rosdakarya.

Widodo, S. A. (2015). Motivasi Siswa Kelas IV dan $V$ Saat Mengikuti Pembelajaran Bolavoli di SD Negeri Terbahsari Kecamatan Wates Kulon Progo. Fakultas Ilmu Keolahragaan: Universitas Negeri Yogyakarta.

Widiastuti. (2011). Tes dan Pengukuran

Olahraga. Jakarta: Bumi Timur Jaya

William, K. C., \& William, C. C. (2011). Five Key Ingredients For Improving Student Motivasion. Research in Higher educatin journal, 12, 1-23.

Zaini, A. (2015). Bermain Sebagai Metode Pembelajaran Bagi Anak Usia Dini. Jurnal Inovasi Pendidikan Guru Raudhatul Athfal, 3(1), 118-134. 
Zuhrotilanwar, A., \& Hartoto, S. (2017). The Influence of The Application of The Game on Improving Motor Skills and Student Learning Motivation in Learning Physical Sport and Health Education (PSHE). Journal of Physical Education, Health and Sport, 4(2), 59-62 